\title{
The gender, social and cultural influences on the management and use of unconditional cash transfers in Niger: a qualitative study
}

\author{
Jennifer Scott ${ }^{1,2, *}$, Caroline Marquer ${ }^{3}$, Fatou Berthe ${ }^{4}$, Eric-Alain Ategbo ${ }^{5}$, Rebecca F Grais ${ }^{3}$ \\ and Céline Langendorf ${ }^{3}$ \\ 'Beth Israel Deaconess Medical Center, Department of Obstetrics and Gynecology, 330 Brookline Avenue, \\ Boston, MA 02215, USA: 'Brigham and Women's Hospital, Division of Women's Health, Boston, MA, USA: \\ ${ }^{3}$ Epicentre, Paris, France: ${ }^{4}$ Epicentre, Niamey, Niger: ${ }^{5}$ UNICEF, Niamey, Niger
}

Submitted 7 May 2016: Final revision received 22 January 2017: Accepted 1 February 2017: First published online 6 March 2017

\begin{abstract}
Objective: The current qualitative study aimed to identify gender, social and cultural influences on the management and use of unconditional cash transfers as part of a prospective intervention study in Niger.

Design: In February to March 2012, focus group discussions and semi-structured individual interviews were conducted with female caregivers of children aged 6 to 23 months who received unconditional cash transfers. Discussion and interview transcripts were analysed using content thematic analysis.

Setting: The study was conducted in the Madarounfa district in Maradi region of Niger.

Subjects: Among forty-eight intervention villages, fourteen were selected for the qualitative study. Participants were randomly selected from eligible households. Results: In total, 124 women participated in focus group discussions or interviews. The majority reported giving the cash transfer to the male head of household who primarily managed cash at the household level. Women reported using a portion of the money to purchase foods for the target child. Feeding the household was the primary use of the cash transfer, followed by health care, clothing, gifts or ceremonies.

Conclusions: Gender, social and cultural norms influenced management and usage of the cash transfer at the household level. The results highlight the importance of integrating gender-sensitive indicators into interventions. Information and awareness sessions should be an integral component of large-scale distributions with a special emphasis on gender equality and the importance of women's empowerment to improve agriculture and family health.
\end{abstract}

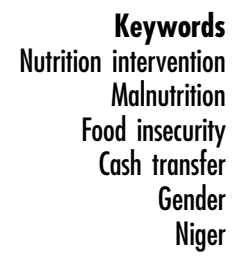

Nutritional interventions using unconditional and conditional cash transfer programmes are increasingly common to address malnutrition among children ${ }^{(1-5)}$. In general, cash transfer programmes are hypothesized to increase household income and purchasing power, allowing households to purchase nutritious foods and providing household food security ${ }^{(3,6)}$. While cash transfer programmes may improve child health in low- and middle-income countries ${ }^{(6-11)}$, there is mixed evidence on the prevention of malnutrition ${ }^{(1,12)}$. The impact of cash transfers on malnutrition is complex to measure as cash transfers are often applied towards food and basic needs, and interventions have not systematically measured changes in nutritional outcomes ${ }^{(13)}$.
In humanitarian contexts, there is increasing emphasis on the use of cash transfer programmes ${ }^{(14)}$ and a growing body of evidence on the impact of cash transfer programmes as part of nutritional interventions. In countries such as Niger, where there is an annual 'lean season' or 'hunger gap', seasonal unconditional cash transfer (UCT) programmes to prevent and address child malnutrition have been conducted and evaluated using various study designs ${ }^{(5,15,16)}$. We conducted a prospective intervention study in Niger to assess whether distributions of supplementary foods reduced more effectively malnutrition in children aged 6 to 23 months compared with household support by cash transfer, and found that preventive distributions combining a supplementary food and UCT had a better preventive effect 
on moderate acute malnutrition and severe acute malnutrition than cash transfer alone or supplementary food alone ${ }^{(5)}$. A pre-post intervention observational study of a UCT nutritional intervention in Niger showed improvement in living standards of poor and very poor households, such as reduced poverty-related indicators and improved food security, and an improvement in anthropometric outcomes for children; however, not all improvements could be attributable to the UCT programme ${ }^{(1)}$. There is current debate about the timing and duration of UCT programmes, with an ongoing trial to evaluate the effectiveness of UCT starting prior to the lean season and of longer duration ${ }^{(15)}$.

Nutritional interventions are based on the hypothesis that the potential benefit of distributions on the health of the target children depends on the intervention components; however, other factors also play a role, such as how UCT cash transfers are used and whether they are divided among members of the household or other individuals. In emergency and transitional contexts, the impact of cash transfers on causes of malnutrition depends on the nature and severity of the crisis, level of poverty, level of education and types of livelihoods affected ${ }^{(13)}$. While a recent humanitarian panel on cash transfers concluded that people spend cash on what they need most ${ }^{(14)}$, it is likely that there are numerous influences on the use of cash at the household level. Understanding these influences could inform the design, implementation and evaluation of nutrition interventions ${ }^{(8,17)}$.

Data from non-humanitarian settings emphasize that it is important to consider how cash transfer programmes are linked to gender and social policies, including women's economic autonomy and equality ${ }^{(18)}$. The majority of nutritional interventions utilizing cash transfer programmes distribute the cash transfers to females, but guidelines are lacking about how to address gender dynamics at the household level that may influence the use and management of the cash transfer. Findings from the pre-post intervention in Niger described above showed a decline in women's well-being and women's autonomy ${ }^{(1)}$. In comparison, a report comparing cash transfer programmes in three countries found an overall positive impact on gender relations, but noted the impact of cash transfer programmes on gender and power dynamics depends on the cultural and social context ${ }^{(19)}$.

Although there has been some progress in recent years ${ }^{(20)}$, Niger lags behind in terms of social inclusion and gender equality. The average age of marriage for women in Niger is $\mathbf{1 5 . 7}$ years and use and/or knowledge of contraception remains low at $12 \%$, overlaid on the highest natality rate in the world ${ }^{(21)}$. The vast majority of the country relies upon subsistence agriculture comprised of small farms, with women playing a pivotal role in the production, processing and sale of goods. Recent research has shown that women are far less empowered in households where a male is also present ${ }^{(22)}$. The relative disempowerment status of women has a particularly negative effect on agricultural production and productivity. In addition, although Niger is a secular state, close to the entire population identifies as Muslim. Empowerment of women has also come to the forefront as an issue over the past decade among religious leaders as a means to reduce the potential spread of more extremist elements in the country, which is surrounded by security threats $^{(23)}$.

We hypothesized that gender, social and cultural norms may influence management and use of cash transfers at the household level in Niger. We conducted a qualitative study, as part of a prospective intervention study in Niger ${ }^{(5)}$, to identify the management and use of the cash transfers, their perceived impact and any gender, social and cultural influences.

\section{Methods}

\section{Intervention study design}

Niger, a country in the Sahelian region of sub-Saharan Africa, endures recurrent food insecurity. There is one harvest per year, preceded by an annual lean season from June to October, which results in acute and chronic malnutrition, especially among children aged 6-23 months ${ }^{(4,24-28)}$. In the prospective intervention study, all children 6 to 23 months of age living in forty-eight villages in the Madarounfa district in Maradi region along the southern border of Niger with Nigeria were assigned to one of seven intervention groups. From August to December 2011, four groups of the seven intervention groups received cash transfers with or without supplementary food (Table 1). The remaining three intervention groups did not receive cash transfers. In the study area, the major ethnic group is Hausa, a predominantly patriarchal group. We included some Fulani villages (campment) as this matriarchal group was hypothesized to behave differently from the Hausa households.

As part of the intervention in those four groups, enrolled female caregivers received a monthly distribution of a cash transfer with or without nutritional supplement for five months and participated in monthly educational sessions including nutritional education on purchasing appropriate food for the target child. The four groups with cash transfers included 3192 children.

Cash transfers were distributed in Francs de la Communauté Financière Africaine (FCFA). Caregivers in nutritional supplement and cash transfer groups received a monthly distribution of 25000 FCFA (approximately €38, \$US 52, 7500 Nigerian Naira). Caregivers in cash transfer only groups received a monthly distribution of 28000 FCFA (approximately €43, \$US 59, 8400 Nigerian Naira). These amounts were recommended by the Government of Niger, concordant with other regional organizations ${ }^{(25)}$ and calculated based on what an average household (seven persons) would need to purchase basic food commodities for an energy requirement of $8786 \mathrm{~kJ}(2100 \mathrm{kcal}) /$ person per $\mathrm{d}$. 
Table 1 Composition of monthly distributions in the intervention groups receiving cash transfer, Madarounfa district in Maradi region of Niger, August to December 2011

\begin{tabular}{llc}
\hline Intervention group & Nutritious supplementary food for children under 2 years of age & Cash transfer \\
\hline HQ-LNS/Cash & Supplementary Plumpy ${ }^{\circledR}, 2092 \mathrm{~kJ}(500 \mathrm{kcal}) / \mathrm{d}$ & 25000 FCFA $(€ 38)$ \\
MQ-LNS/Cash & Plumpy'Doz ${ }^{\circledR}, 1046 \mathrm{~kJ}(250 \mathrm{kcal}) / \mathrm{d}$ & 25000 FCFA $(€ 38)$ \\
SC+/Cash & Super Cereal Plus, $3431 \mathrm{~kJ}(820 \mathrm{kcal}) / \mathrm{d}$ & 25000 FCFA $(€ 38)$ \\
Cash only & - & 28000 FCFA $(€ 43)$ \\
\hline
\end{tabular}

HQ-LNS, high-quantity lipid-based nutrient supplement; Cash, unconditional cash transfer; MQ-LNS, medium-quantity lipidbased nutrient supplement; $\mathrm{SC}+$, Super Cereal Plus; FCFA, Franc de la Communauté Financière Africaine (Financial Community of Africa franc).

Households in the Madarounfa district live on approximately 500 FCFA per day (approximately $€ 0 \cdot 75$, \$US 1$)^{(29)}$. As the study region borders Nigeria, currency is reported in the unit reported by the participant. Details on the study design and results have been published previously ${ }^{(5)}$.

\section{Qualitative study design}

A qualitative study was conducted from 20 February to 6 March 2012 in fourteen of the forty-eight intervention villages. Two villages from each of the seven intervention groups were selected. The village with the largest population, closest health-care facility and market, and major road and the village with the smallest population and most remote location were selected in each intervention group. Among the fourteen villages, eight villages received cash transfers with or without supplementary food. Data from those eight villages receiving cash transfers are presented herein. Available female caregivers of children enrolled in the intervention study were randomly selected from an exhaustive list of participants and invited to participate in either a focus group discussion or individual interview. Only one woman per household was eligible to participate.

\section{Ethical considerations}

Prior to implementing the qualitative study, the study protocol was approved by the National Consultative Ethics Committee of Niger, Ministry of Public Health of Niger and the Comité de Protection des Personnes, Ile-de-France XI. The head of each selected village was informed of the study objectives and procedures and agreed to participate. Participation in the study was voluntary and all participants signed an informed consent form. No identifying information was collected from the participants.

\section{Qualitative data collection}

In each selected village, two focus group discussions comprising six to eight caregivers and one to two individual interviews were conducted. Discussions and interviews lasted 60 to $90 \mathrm{~min}$ and consisted of openended and semi-directed questions focused on usage and perceptions of distributed supplementary foods (topic 1) and cash transfers (topic 2). In the villages receiving cash transfer only, all discussions and interviews focused on topic 2. The study team was independent from the intervention team. Following a three-day training, female Nigerien community health workers facilitated discussions and conducted interviews in private settings. F.B., a medical doctor with experience in qualitative data collection, was assisted by a translator and supervised discussions and a subset of interviews. Discussions and interviews were conducted in Hausa and audio-recorded with permission from participants. The discussions and interviews were transcribed in French by a local translator and verified by F.B. Then they were translated from French to English by a translator and accuracy of the translated transcript was verified by C.M. and C.L.

\section{Qualitative data analysis}

Electronic files of transcripts were uploaded and organized in Microsoft ${ }^{\circledR}$ Word 2010 and manually coded. Data from the focus group discussions and the interviews focusing on cash transfers were analysed together and not separately. The qualitative data on supplementary food were analysed separately and will be reported elsewhere.

Thematic content analysis was applied as a method to systematically code the text data and to identify themes and patterns ${ }^{(30,31)}$. Both deductive and inductive approaches to data analysis were utilized ${ }^{(32,33)}$. General categories were outlined based on prior research and previously analysed quantitative data from the present study. Additional codes and categories were directly derived from the data including beliefs, opinions, social pressures and social norms.

Two researchers read the transcripts line by line and labelled concepts. Major themes and sub-themes were identified within and across categories and the following broad themes were identified: (i) management of the cash transfer; (ii) use of the cash transfer; and (iii) perceived impact of the cash transfer. Throughout the process, the researchers triangulated the qualitative data with the previously analysed quantitative data and the existing literature. The constant comparative technique was applied, but the iterative process of concurrent data collection and analysis was not conducted due to study logistics and translation of interview transcripts. The phrases most illustrative of opinions, perceptions and behaviours most 
Table 2 Number of women in cash transfer groups included in the qualitative study, Madarounfa district in Maradi region of Niger, February to March 2012

\begin{tabular}{lccc}
\hline & \multicolumn{3}{c}{ Focus group discussions } \\
\cline { 2 - 3 } Intervention group & Topic 1: Nutritious supplementary food & Topic 2: & \\
\hline HQ-LNS/Cash & 16 & 15 & 2 \\
MQ-LNS/Cash & 16 & 14 & 2 \\
SC+/Cash & 15 & 16 & 1 \\
Cash & - & 27 & 0 \\
TOTAL & 47 & 72 & 5 \\
\hline
\end{tabular}

HQ-LNS, high-quantity lipid-based nutrient supplement; Cash, unconditional cash transfer; MQ-LNS, medium-quantity lipid-based nutrient supplement; $\mathrm{SC}+$, Super Cereal Plus.

frequently expressed are reported, as well as examples of isolated and unique behaviour ${ }^{(34)}$. The currency reported by the participants was kept in the quotes. Some participants, living in villages closed to the Nigeria's borders, used Nigerian Naira, while other participants used FCFA.

\section{Results}

In eight selected villages where participants received cash transfers with or without supplementary foods, 124 female caregivers participated in focus group discussions and/or were interviewed (Table 2). Demographic data were not collected. Qualitative data, noting study group (see Table 1 for a description of the abbreviations used) and village, are reported below.

\section{Management of the cash transfer}

The majority of women reported that the cash was given to men immediately upon return to the household. In most cases, the money was divided to manage household expenses:

'It's the men who manage the money. In my home, we divide the money into two parts. One part is assigned to expenses for the child who is the beneficiary and the other part to buying grain for the family.' (HQ-LNS/Cash group, Garin Gonao)

'When you are given 28000 FCFA each month, as soon as you get to the house, if your husband is home you give him the money.' (Cash group, $\mathrm{Na}$ Anfana)

Explanations for why money was given to men reflected gender norms in the household and community:

'Everything that the wife will have is up to the husband to keep, so that it doesn't cause any problems between them.' (Cash group, Na Anfana)

'We give the money to our husbands because it is the husbands' duty to provide food for us.' (MQ-LNS/Cash group, El Kokia)
In households where money was divided, the majority of women managed 5000-10000 FCFA:

'We received 25000 FCFA, and I took 5000 FCFA, I bought eggs, fish, [...] beans for the child, the 20000 FCFA that were left over I gave to my husband who bought corn and sorghum for the whole family to eat.' (HQ-LNS/Cash group, Doutchin Begoua)

'At the first distribution, my husband didn't take all of the money; he took 15000 FCFA and left us 10000 FCFA. With the money that he took, he left to buy provisions. With the amount that he gave me, he said that we could buy provisions to make food to eat when he was gone, because he is not always at the house.' (SC +/Cash group, Dan Gaya)

Few women expressed sole management of the distributed money. This practice occurred more often in a primarily Fulani village:

'[My husband] buys things with his own money. What we are given belongs to us, the mothers; when you need something you take some of the money to buy it.' (MQ-LNS/Cash group, Oudel Campement)

Some women discussed with their husbands management of the money:

'When I returned from the site, I gave the money to my husband and we sat down to discuss how to use the money. Each month we divided the money into three parts: one part to buy provisions for the whole family, another part that we kept in case of illness because at that time even when our husbands left to find work they didn't find any, and so if someone became ill we would use this money to pay for treatment, and the last part is for buying nutritious foods for the target child like fish, bean purée. And that's how we managed the money until the Tabaski festival.' (Cash group, Na Anfana)

'We give [cash] to the husband who manages money but we first discuss, then there are 10000 FCFA that are kept for the target child and the remaining is invested in the household.' (SC+/Cash group, Gamdji) 


\section{Use of the cash transfer}

The cash transfer was most commonly used to buy food, with men responsible for buying grain and women responsible for buying other foods. A portion of the cash transfer was reserved for the target child:

'With 20000 FCFA we bought provisions and with 5000 FCFA we gave to his brother to take him to the dispensary to take care of him; with 5000 FCFA we bought millet, with 5000 FCFA corn and 5000 FCFA to buy beans, and the rest the 5000 FCFA for buying oil, liver, some biscuits for the target child.' $(\mathrm{SC}+/$ Cash group, Dan Gaya)

'My husband keeps the money but he gives me 4000 Naira for the child's expenses and the rest is designated for family expenses. From the 4000 Naira, 2000 Naira are strictly reserved for the child for buying milk, biscuits, eggs, beans so that he gets bigger and the other 4000 Naira are used by my husband to buy provisions for the family.' (HQ-LNS/ Cash group, Garin Gonao)

Participants reported that the money was also applied to health expenses, as well as expenses related to the extended family:

'Three of my children had malaria at the time of different distributions so I took each one to the health centre because I was afraid that they would tell me that my children were anaemic and I paid 1100 FCFA per child and per treatment.' (MQ-LNS/ Cash group, El Kokia)

'Honestly I was happy, because my father was sick at the time of the third distribution, I gave him 5000 FCFA to go be taken care of.' (MQ-LNS/Cash group, El Kokia)

Participants reported spending money for ceremonies (deaths, births, baptisms and marriages) and festivals:

'When I gave birth, my husband didn't have any money so he postponed the baptism. And so he took 15000 FCFA to buy a goat for the baptism.' (MQ-LNS/Cash group, El Kokia)

'Without this money, my children would not have had outfits for the festival of Ramadan, I took 750 Naira to buy clothes for them; I took 1500 Naira for my wraps; 500 Naira to have them sewn.' (HQ-LNS/ Cash group, Doutchin Begoua)

Gifting money to kin who did not receive distributions was commonly reported and evoked by tradition and social convention. However, some women stated that they did not use money from distributions as gifts:

'There is a sort of custom in the village: when you receive aid, it must be shared symbolically with the others.' (Cash group, Na Anfana)
'I don't share with anyone and that is quite simply because the money was given to satisfy the nutritional needs of the child and the family, so I cannot help someone to handle their health costs.' (MQ-LNS/Cash group, Oudel Campement)

Sharing the family meal was commonly described and motivated by social custom, respect, generosity and concern for equality:

'When you are eating, you will not let the other children cry from hunger so in one way or another, the whole family benefits [from the distributions].' (HQ-LNS/Cash group, Doutchin Begoua)

'In a large family, you cannot eat all by yourself and let the other members of the family go hungry. For example, I can give them a half-measure of flour or if I am preparing food, I take some out to give to them! And so we shared with relatives, friends and neighbours too for three months.' (Cash group, Korama Gora)

There were rare reports of saving the distributed money:

'Our food production was not depleted even four months after the harvest and so this money, we took advantage of it to save money, we bought provisions to store in addition to what we harvested from our fields.' (SC+/Cash group, Dan Gaya)

\section{Perceived impact of the cash transfer}

Participants noted that the money permitted them to vary the food for the target child and improve the child's health:

'We noticed many changes, our children recovered from their malnourished state; with the money when you buy something for the child, he eats it and goes and plays with the others [...]. When we didn't have this money, there is nothing to give to the children and the child is always clinging to his mother and crying because he is hungry but with this money that doesn't happen.' (Cash group, Na Anfana)

'Before our children suffered from fevers, diarrhoea and vomiting but now that there is money, we don't have this problem anymore.' (Cash group, $\mathrm{Na}$ Anfana)

The cash transfer increased nutritional resources for the household during lean periods and diversified diet:

'Before the arrival of the cash we didn't eat certain categories of food like pasta, rice and vitamin-rich foods that our children eat now, but now thanks to the cash our diet is varied.' (MQ-LNS/Cash group, Oudel Campement) 
'Receiving the cash has really shortened the lean period within households. Because as long as the cash was arriving at the house, the harvests were secured and thus the lean period was decreased.' (HQ-LNS/Cash group, Garin Gonao)

Income-generating activities and household organization also shifted; with women reporting more time to work in the fields and that their husbands were away less. Some women ceased income-generating activities in order to work in their households, while others reported new activities:

'Before the distribution, I worked in other peoples' fields to earn something to buy provisions, but when the distribution money arrived I stopped, since then I use my time to work in my own field. I don't go back to working in other peoples' fields unless I see that the provisions are gone and it isn't distribution time yet.' (SC+/Cash group, Dan Gaya)

'Before this support, our men would go work as hired hands in other peoples' fields. They sent their children to cultivate their own fields. This could lead to a poor harvest from their field because when you compare how an adult weeds and how a child weeds, the result is not the same.' (Cash group, Korama Gora)

In contrast, some women noted the cash transfer did not influence activities:

'I sell milk and I can't under any circumstances use the support money because I tell myself that one day it will end. And so it hasn't had an impact on my activity.' (MQ-LNS/Cash group, Oudel Campement)

'We continued to do all the activities that we did before, even with the money.' (Cash group, Na Anfana)

While cash transfers may have affected social relations within the community, the social convention of sharing was most dominant:

'Our relationships with the inhabitants of other villages have deteriorated and they have even lost contact [with us] because they do not have support and we have support.' (Cash group, Na Anfana)

'No, we have not had any problems with that money, those who had and those who did not have we are all happy and satisfied with that! [...] you cannot eat alone and let them starve! You always have to share with them.' (Cash group, Korama Gora)

\section{Discussion}

The current study provides qualitative data on the management, use and perceived impact of cash transfers as part of a nutritional intervention utilizing UCT to prevent acute malnutrition among children in Niger. The findings highlight how gender, cultural and social norms influenced the management and usage of the cash transfer at the household level.

One of the most important findings regarding management of the cash transfer was that men managed the distributed money, despite women receiving the cash distributions. This practice likely reflects gender norms in sampled households and was also described in other cash transfer programmes in Niger ${ }^{(1,4)}$. Globally, women are the primary recipients in cash transfer programmes with the rationale that giving money to women will impact women's empowerment by increasing access to resources and contribution to household decision making ${ }^{(8)}$ and that money spent by women will positively impact the well-being of children and the household ${ }^{(18)}$. However, our findings reveal that even when women received cash at the point of distribution, most of the money was directly given to men. Our findings support recommendations to incorporate gender into cash transfer programmes ${ }^{(17)}$ such as engaging men in programme activities and including gender-sensitive indicators in evaluations of nutrition interventions using cash transfers ${ }^{(18)}$.

Further gender influences on the management of cash transfers emerged from the qualitative data and our findings support that cash transfers may impact underlying and interrelated gender and socio-economic factors ${ }^{(13)}$. Participants reported that men are responsible for purchasing household resources; the rare reports of women solely managing the cash transfer were noted within a Fulani community known for a matriarchal legacy in its social system. Among households who divided the cash transfer, some described dialogue about its use, but not all. While our study did not evaluate household decision making, a UCT programme in Niger found that women's decision making declined significantly related to the cash transfer ${ }^{(1)}$. A noted limitation of cash transfer programmes is that they reinforce traditional roles and social expectations of women within households, rather than transforming gender relations ${ }^{(11,18,35)}$. Our study did not directly evaluate gender inequality and the risk of gender-based violence as a result of the cash transfer programme, nor was violence spontaneously disclosed in the focus group discussions or interviews. But given the potential impact of violence as a result of the cash transfer as noted in other research ${ }^{(36)}$, it is important to assess in future evaluations of nutritional interventions utilizing cash transfer programmes.

Across intervention groups, money from the cash transfer was primarily used for food, followed by health care, clothing and gifts. Notably, the described purchased foods followed recommended guidelines and highlight the importance of educational sessions, as noted in another study ${ }^{(2,37)}$, and participants noted that the cash increased diet diversity as described in other research ${ }^{(38)}$. Given the gender norms discussed above in regard to the male head 
of household primarily managing the cash transfers, engaging men in education sessions should be considered. Across all study groups, approximately 20-40\% (500010000 FCFA) of the monthly distribution was reported to be spent on foods for the target child. Another cash transfer programme in Niger evaluated households' use of monthly cash distributions and found that the majority of cash was spent on food for the household compared with food for the target child, among other noted uses such as ceremonies, funerals and baptisms ${ }^{(4)}$. While it can be challenging to directly compare cash transfer programmes, due to different approaches and different amounts of cash transfers, the data highlight the importance of considering the amount of the cash transfer in the context of household size and needs. Furthermore, a UCT was selected for this intervention and is more commonly used in this context, given that conditional cash transfers are often contingent on other community resources, which may be limited in crisis settings. Future research could explore the timing, duration and type of cash transfer programmes most appropriate for crisis contexts and most effective for reaching target beneficiaries.

The use of the cash transfers for gifts and ceremonies reflects traditional social and cultural norms of cooperation, sharing and solidarity. Gifting money to people outside the household and non-monetary gifting were described. Gifting was more common during two months of the intervention (August and September), corresponding to the period preceding the harvest and likely representing peak food insecurity. Furthermore, two Muslim holidays occurred during the intervention, which likely encouraged gifting and festivals. Giving money to kin who do not receive distributions was commonly reported and was motivated by social convention and concern for social equality. Prior socio-economic studies in the Maradi region of Niger documented the phenomenon of gifts and reciprocal gifts of food and its relationship to social organization ${ }^{(39)}$. Another study on cash transfers found that sharing of cash was influenced by cultural customs ${ }^{(3)}$; however, gifting of cash transfers has not been extensively documented in evaluations of nutrition interventions. Further dialogue on social and cultural influences on the use of cash transfers could inform future interventions, including how interventions are integrated into broader social protection programmes and policies.

The qualitative data highlight perceived impacts, both positive and negative, of the cash transfer programme. Participants reported that cash transfers influenced revenue-generating activities, similar to changes noted in another UCT programme in Niger ${ }^{(1)}$. In regard to the impact on income-generating activities, the qualitative data describe some positive effects, including reduction of child labour and increased investment for home production as described in other studies ${ }^{(40,41)}$. However, it is important to consider the sustainability of such changes as part of a short-term UCT programme. The UCT used in the present study came from a dedicated fund specific to the study, but in order for the programme to be expanded additional outside investment of dedicated governmental funds would be needed with long-term commitment. This may be feasible in the short term, for example during emergency interventions, but as a sustainable policy option, UCT presents significant constraints.

Finally, the qualitative data provide further context to the quantitative findings of the prospective intervention study $^{(5)}$. These qualitative findings suggest that UCT were used at least partially towards ensuring food security for the household and improving the nutritional quality of the diet of young children. This also highlights the importance of the nutrition information sessions provided by the study team to mothers and to the community. However, the results of the prospective intervention study showed that distributions which combine a nutritious supplementary food with cash transfer are likely more effective at preventing acute malnutrition than UCT alone. This, in addition to issues of sustainability, highlights the ongoing importance of providing fortified foods (e.g. fortified blended flours) for young children. Further, fortified foods, which have increased content of essential micronutrients, have been shown to be more cost-effective at meeting nutrient requirements compared with natural foods ${ }^{(42-45)}$.

\section{Limitations}

As in other qualitative studies, the results may not be representative of all study beneficiaries. However, a large number of individuals were interviewed, representing diverse villages and varied perceptions and experiences. The majority of data represents focus group discussion data; there were only five individual interviews and no interviews from the cash only group. It is possible that opinions expressed in focus groups may have differed from opinions expressed during interviews. It is important to also consider social desirability bias in participants' expressed opinions of the cash transfer programme. Despite emphasizing that participation would not impact distributions, responses may have been influenced by concern of not receiving further distributions. There may have been interviewer bias in the way the focus group discussions or interviews were conducted; we attempted to minimize this through training, through recruitment of facilitators and interviewers, and through supervision of the groups by someone with expertise in qualitative data collection. Although all efforts were made to ensure that interviews were transcribed and translated appropriately, there may have been translation imprecision. Additionally, the qualitative study was conducted three months after the last cash transfer. While there could be recall bias, this effect is likely minimal as the distributions were significant to beneficiary households, and discussions and interviews were focused on the relevant period. 


\section{Conclusions}

The findings reveal important gender, social and cultural influences on the management, use and perceived impact of UCT as part of a nutritional intervention to prevent acute malnutrition among young children in Niger. Future research could explore strategies and frameworks to integrate gender, social and cultural norms into planning, implementation and evaluation of emergency nutritional interventions. Specifically, information and awareness sessions for recipients and the community as a whole should be an integral component of large-scale distributions with a special emphasis on gender equality and the importance of women's empowerment to improve agriculture and family health. Overall, gender transformation within households as the locus of sexual and reproductive health, family planning and child health should be encouraged.

\section{Acknowledgements}

Acknowledgements: The authors wish to thank the families that participated in this study. They would like to acknowledge the Ministry of Health and in particular the Division of Nutrition, Niger. They also wish to thank ASUSU, the Nigerien association that distributed cash to beneficiaries, and the WFP-Niger for their help with the implementation of the nutritional interventions. Financial support: This work was supported by Médecins Sans Frontières and UNICEF. Epicentre receives core funding from Médecins Sans Frontières. Médecins Sans Frontières and UNICEF had no role in the design, analysis or writing of this article. Conflict of interest: The authors declare no conflicts of interest. Authorship: J.S. interpreted the data and contributed to the writing of the manuscript. C.M. conceived and designed the study, analysed the data and contributed to the writing of the manuscript. F.B. carried out the study and enrolled participants. E.-A.A. formulated the research questions and conceived and designed the study. R.F.G. formulated the research questions and contributed to the writing of the manuscript. C.L. conceived and designed the study, analysed and interpreted the data and contributed to the writing of the manuscript. Ethics of buman subject participation: This study was conducted according to the guidelines laid down in the Declaration of Helsinki and all procedures involving human subjects were approved by the National Ethical Committee of Niger's Ministry of Public Health. Written informed consent was obtained from all subjects.

\section{References}

1. Fenn B, Noura G, Sibson V et al. (2014) The role of unconditional cash transfers during a nutritional emergency in Maradi region, Niger: a pre-post intervention observational study. Public Health Nutr 18, 343-351.
2. Wakoli AB, Ettyang GA \& Lakati AS (2012) Undernutrition of orphans and vulnerable children: a comparison of cash transfer beneficiaries and non beneficiaries in Korogocho slums, Nairobi. East Afr J Public Health 9, 132-138.

3. Owusu-Addo E (2016) Perceived impact of Ghana's conditional cash transfer on child health. Health Promot Int 31, 33-43.

4. Poulsen L \& Fabre D (2010) Evaluation Report. 2010 Niger: Evaluation of Cash Transfer for Protection of Blanket Feeding. République du Niger: UNICEF.

5. Langendorf C, Roederer T, de Pee S et al. (2014) Preventing acute malnutrition among young children in crises: a prospective intervention study in Niger. PLoS Med 11, e1001714.

6. Cecchini S \& Soares FV (2014) Conditional cash transfers and health in Latin America. Lancet 385, 32-34.

7. Owusu-Addo E \& Cross R (2014) The impact of conditional cash transfers on child health in low- and middle-income countries: a systematic review. Int J Public Health 59, 609-618.

8. Bassett L (2008) Can Conditional Cash Transfer Programs Play a Greater Role in Reducing Child Undernutrition? SP Discussion Paper no. 0835. Washington, DC: The World Bank.

9. Paes-Sousa R, Santos LM \& Miazaki ES (2011) Effects of a conditional cash transfer programme on child nutrition in Brazil. Bull World Health Organ 89, 496-503.

10. Oliveira Assis AM, Ribas de Farias Costa P, Monteiro Silva MD et al. (2014) Effectiveness of the Brazilian conditional cash transfer program - Bolsa Alimentacao - on the variation of linear and ponderal increment in children from Northeast of Brazil. Nutr Hosp 31, 689-697.

11. Fultz E \& Francis J (2013) Cash Transfer Programmes, Poverty Reduction and Empowerment of Women: A Comparative Analysis. Experiences from Brazil, Chile, India, Mexico and South Africa. Working Paper no. 4/2013. Geneva: International Labour Organization.

12. Manley J, Gitter S \& Slavchevska V (2012) How Effective are Cash Transfer Programmes at Improving Nutritional Status? A Rapid Evidence Assessment of Programmes' Effects on Anthropometric Outcomes. London: EPPI-Centre, Social Science Research Unit, Institute of Education, University of London.

13. Bailey S \& Hedlund K (2012) The Impact of Cash Transfers on Nutrition in Emergency and Transitional Contexts: A Review of Evidence. London: Humanitarian Policy Group, Overseas Development Institute.

14. Overseas Development Institute (2015) Doing Cash Differently: How Cash Transfers Can Transform Humanitarian Aid. Report of the High Level Panel on Humanitarian Cash Transfers. London: Overseas Development Institute.

15. Sibson VL, Grijalva-Eternod CS, Bourahla L et al. (2015) The REFANI-N study protocol: a cluster-randomised controlled trial of the effectiveness and cost-effectiveness of early initiation and longer duration of emergency/seasonal unconditional cash transfers for the prevention of acute malnutrition among children, 6-59 months, in Tahoua, Niger. BMC Public Health 15, 1289.

16. Tonguet-Papucci A, Huybregts L, Ait Aissa M et al. (2015) The MAM'Out project: a randomized controlled trial to assess multiannual and seasonal cash transfers for the prevention of acute malnutrition in children under 36 months in Burkina Faso. BMC Public Health 15, 762.

17. Marshall C \& Hill PS (2015) Ten best resources on conditional cash transfers. Health Policy Plan 30, 742-746.

18. Soares FV \& Silva E (2010) Conditional Cash Transfer Programmes and Gender Vulnerabilites: Case Studies of Brazil, Chile, and Colombia. Working Paper \#69. Brasilia: International Policy Centre for Inclusive Growth (IPC-IG), United Nations Development Programme. 
19. Brady C (2011) Walking the Talk: Cash Transfers and Gender Dynamics. Oxford: Concern Worldwide and Oxfam GB.

20. GBD 2015 Child Mortality Collaborators (2016) Global, regional, national, and selected subnational levels of stillbirths, neonatal, infant, and under-5 mortality, 1980-2015: a systematic analysis for the Global Burden of Disease Study 2015. Lancet 388, $1725-1774$.

21. The World Bank (2016) Marriage, Contraceptive use and Birth Rate. Washington, DC: The World Bank.

22. Wouterse F (2016) Empowerment matters: 'invisible women' in Niger produce less food. IFPRI Blog, 5 January. http://www. ifpri.org/blog/empowerment-matters-\%E2\%80\%9Cinvisiblewomen\%E2\%80\%9D-niger-produce-less-food (accessed February 2017).

23. Robinson PT (2005) Islam and Female Empowerment in Niger: Research Note. Boston, MA: Tufts University.

24. Burki TK (2013) Malaria and malnutrition: Niger's twin crises. Lancet 382, 587-588.

25. Save the Children (2009) How Cash Transfers Can Improve the Nutrition of the Poorest Children: Evaluation of a Pilot Safety Net Project in Southern Niger. London: Save the Children.

26. Institut National de la Statisque, République du Niger (2004) Niger - Enquête sur la vulnérabilité alimentaire des ménages au Niger en 2010. Niamey: INS.

27. Institut National de la Statisque \& ICF International (2013) Enquête Démographique et de Santé et à Indicateurs Multiples (EDSN-MICS IV) du Niger 2012. Calverton, MD: INS and ICF International.

28. Institut National de la Statisque, République du Niger (2011) Enquete sur la Securité Alimentaire des Ménages au Niger. Niamey: INS.

29. Save the Children (2009) Understanding Household Economy in Rural Niger. London: Save the Children.

30. Priest H, Roberts P \& Woods L (2002) An overview of three different approaches to the interpretation of qualitative data. Part 1: Theoretical issues. Nurse Res 10, 30-42.

31. Hsieh HF \& Shannon SE (2005) Three approaches to qualitative content analysis. Qual Health Res 15, 1277-1288.

32. Cavanagh S (1997) Content analysis: concepts, methods and applications. Nurse Res 4, 5-16.

33. Elo S \& Kyngas H (2008) The qualitative content analysis process. J Adv Nurs 62, 107-115.

34. Denzin N \& Lincoln Y (2005) The SAGE Handbook of Qualitative Research. Thousand Oaks, CA: SAGE Publications, Inc.
35. Soares FV \& Silva E (2010) Conditional Cash Transfer Programmes and Gender Vulnerabilities in Latin America: Case Studies from Brazil, Chile and Colombia. London: Overseas Development Institute.

36. Hidrobo M \& Fernald L (2013) Cash transfers and domestic violence. J Health Econ 32, 304-319.

37. Ahmed A, Hoddinott J, Quabili W et al.. (2013) Which Form of Safety Net Transfer is Most Beneficial? Impacts on Income, Food Security and Child Nutrition. Washington, DC: International Food Policy Research Institute.

38. Baye K, Retta N \& Abuye C (2014) Comparison of the effects of conditional food and cash transfers of the Ethiopian Productive Safety Net Program on household food security and dietary diversity in the face of rising food prices: ways forward for a more nutrition-sensitive program. Food Nutr Bull 35, 289-295.

39. Raynaut C (1977) Aspects socio-économiques de la préparation et de la circulation de la nourriture dans un village hausa (Niger). Cab Etud Afr 17, 569-597.

40. Asfaw S, Davis B, Dewbre J et al. (2014) Cash transfer programme, productive activities and labour supply: Evidence from randomized experiment in Kenya. J Dev Stud 50, 1172-1196.

41. Handa S, Davis B, Stampini M et al. (2010) Heterogeneous treatment effects in conditional cash transfer programs: assessing the impact of Progresa on agricultural households. J Dev Effect 2, 320-335.

42. Dewey KG (2013) The challenge of meeting nutrient needs of infants and young children during the period of complementary feeding: an evolutionary perspective. J Nutr 143, 2050-2054.

43. Baldi G, Martini E, Catharina M et al. (2013) Cost of the Diet (CoD) tool: first results from Indonesia and applications for policy discussion on food and nutrition security. Food Nutr Bull 34, 2 Suppl., S35-S42.

44. Ferguson EL, Darmon N, Fahmida U et al. (2006) Design of optimal food-based complementary feeding recommendations and identification of key 'problem nutrients' using goal programming. J Nutr 136, 2399-2404.

45. Hoddinott J \& Bassett L (2008) Conditional Cash Transfer Programs and Nutrition in Latin America: Assessment of Impacts and Strategies for Improvement. Washington, DC: International Food Policy Research Institute. 